\title{
EL AFIJO APLICATIVO - I- DEL SUAHELÍ Y SUS REPERCUSIONES TEÓRICAS PARA LA GRAMÁTICA FUNCIONAL
}

\author{
VENTURA SALAZAR GARCÍA \\ (Universidad de Alicante)
}

\begin{abstract}
The present paper discusses how the Simon C, Dik's Functional Grammar (FG) should account for the applicative affix $-i-i$ in swahili verbs. In order to do so, it first summarizes the theory of syntactic function assignment within the framework of $\mathrm{FG}$; and it also shows $\mathrm{FG}^{\prime}$ 's main differences with the traditional and structural approaches.

According to Dik, the applicative affix $-\mathbf{i}$ - expresses the object assignment to a beneliciary term. Nevertheless, there are some empirical difficulties against this hypothesis. It is therefore suggested the possibility of considering the affix - $\mathrm{i}-$ not as a consequence of a syntactic function assignment, but as a synchronically productive lexical procedure which builds up derived verbal predicates.
\end{abstract}

\section{Introducción}

A lo largo de las últimas décadas, el modelo gramatical diseñando por el lingüista holandés Simon C. Dik (1940-1995) ha alcanzado unos niveles considerables de desarrollo e implantación dentro del complejo panorama de la linguística contemporánea. Dicho modelo, conocido generalmente como 'Gramática Funcional' (en adelante: GF), ha sido perfilado paulatinamente por medio de diversas publicaciones, entre las que citaré de modo particular las de Dik $(1978,1989$ y 1997)', Siewierska (1991) y Hengeveld (1992). Sin duda, una de las

\footnotetext{
'El libro de Dik (1997), que constituye hoy en día la exposición más completa y sistemática de esta teoría, fue publicado póstumamente en dos volúmenes, en una edición llevada a cabo por Kees Hengcveld. El primer volumen, dedicado a la estructura de la cláusula, ofrece esencialmente una
} 
principales claves del éxito de la GF reside en el hecho de que sus postulados disponen de una solidez nada desdeñable por lo que se refiere a su adecuación tipológica. La GF ha contado desde sus comienzos con importantes indicios a su favor a partir del análisis de muestras de lengua extraídas de un amplio número de idiomas muy alejados genética y tipológicamente entre sí. Este hecho, unido al alto grado de formalización y explicitud con el que ha sido concebido, hace que el modelo dikeano aparezca en nuestros días como un punto de apoyo de primer orden dentro del marco general del funcionalismo lingüístico.

De lo dicho en el párrafo anterior no debe deducirse, en modo alguno, la impresión errónea de que la GF constituye ya una doctrina totalmente estable y cerrada. Antes al contrario, son muchos los aspectos que aún están necesitados de una formulación más detallada o de una profunda revisión. $\mathrm{Y}$, asimismo, no faltan insosiayables contraejemplos que cuestionan seriamente algunas de sus asunciones teóricas. Ahora bien, todas estas circunstancias, más que socavar los fundamentos esenciales de la GF, dan testimonio del dinamismo que caracteriza actualmente esta propuesta gramatical, así como del abanico abierto de posibilidades que pueden condicionar en un sentido u otro su evolución futura. Buena prueba de todo ello se halla en los múltiples trabajos recientes que profundizan en el papel que ha de ocupar la pragmática dentro de la descripción gramatical, o bien en los que ponen la GF en relación directa con otras teorías lingüísticas ${ }^{2}$ tales como la lexemática, la gramática sistémico-funcional, ciertos desarrollos de la lingüística cognitiva, etc.

Dentro del contexto general que, de modo sumamente escueto, he señalado hasta aquí, el presente artículo aspira a ofrecer un replanteamiento de una cuestión que puede ser considerada ya clásica dentro de la trayectoria y la bibliografía más representativas de la GF. Me refiero al análisis de ciertos afijos propios de la morfología verbal de las lenguas bantúes, y más concretamente a la interpretación que ha de hacerse del afijo aplicativo $-i$ - del suahelî́. Éste es sin duda uno de los problemas más complejos que tiene planteados el estudio de dicha lengua africana, y Simon C. Dik le concedió siempre una singular atención en las distintas monografías dedicadas a la exposición de su modelo. A grandes rasgos, cabe decir

revisión de Dik (1989), mientras que el segundo volumen, dedicado a las construcciones derivadas y complejas, había permanccido inédito hasta ese momento.

${ }^{2}$ Así lo testimonian, por ejemplo, varios de los trabajos publicados en el volumen editado por Olbertz et al. (1998).

${ }^{3}$ Para las denominaciones de lenguas sigo, siempre que me ha resultado posible, las indicaciones de Moreno Cabrera (1990). A continuación recojo también las abreviaturas utilizadas en este artículo. a) Funciones semánticas: ag (agente); ben (beneficiario); instr (instrumento); met (meta); rec (receptor); ubic (ubicación). b) Funciones sintácticas: obj (objeto); suj (sujeto). c) Otras: $A^{\prime}$ (primer argumento); fut (futuro); GF (Gramática Funcional); indic (indicativo); JFS (Jerarquía de Funciones Semánticas); lit. (literalmente); pas (pasivo); pers (persona); plur (plural); pres (presente); pret (pretérito); sing (singular); $\checkmark$ (verbo). 
que, a juicio de este lingüista, el afijo aplicativo - $i$ - del suahelí constituye una marca formal vinculada al proceso de asignación de la función sintáctica objeto. Ahora bien, la validez de esta postura se enfrenta con ciertas dificultades ${ }^{4}$ que han suscitado un interesante debate en el que han participado tanto partidarios como detractores de la GF. Advierto ya desde este momento que mi postura al respecto, que será presentada en estas páginas, se desenvuelve claramente dentro del marco teórico de la GF, pero que, aun así, se muestra contraria a la interpretación dikeana. De hecho, uno de mis objetivos es mostrar que el propio ámbito de la GF permite una cxplicación alternativa, mediante la cual dicho afijo es entendido, no ya como un instrumento sintáctico al servicio de la asignación de la función objeto, sino como un procedimiento, ubicado dentro del componente de base de la gramática, que tiene por finalidad la formación de predicados derivados. Prestaré atención también a algunas de las implicaciones teóricas deducibles de esta propuesta, aunque otras muchas (como su incidencia en aspectos tales como la configuración de la JFS o la caracterización de los argumentos) exigen un análisis más detallado que queda fuera de los márgenes y objetivos del presente trabajo.

Antes de adentrarme en la cuestión nuclear del artículo, he optado por introducir previamente dos apartados que tienen por finalidad situar adecuadamente $\mathrm{cl}$ instrumental teórico del que se hará uso con posterioridad. En el primero de ellos se revisa la doctrina tradicional de las funciones gramaticales a la luz de las condiciones en las que se desenvuelve la lingüística contemporánea. En el segundo sc hacc referencia al papel que desempeñan las funciones sintácticas dentro de la GF. Confío en que se disculpe la extensión de ambos apartados en virtud de la voluntad clarificadora que animó su redacción. Y es que, como muy bien sabe todo lingüista familiarizado con el modelo de Dik, los términos 'sujeto' y 'objeto' tienen en la GF un valor muy diferente al que se le asigna en la terminología lingüística común. Por eso, creo necesario evitar de antemano cualquier posible malentendido al respecto y, al mismo tiempo, justificar las razones que han llevado a la GF hacia este profundo cambio de interpretación de los hechos funcionales.

\section{Las funciones sintácticas en el tránsito de la gramática tradicional a la moderna: crisis y pervivencia}

Tradicionalmente, las funciones sintácticas, entendidas como los vínculos rclacionales que mantienen entre sí los constituyentes de una oración, solían ser definidas sobre la base de ciertas apreciaciones de carácter nocional o formal. La calidad técnica de tales definiciones era, por supuesto, sumamente variable, pues

\footnotetext{
${ }^{4}$ Dificultades probablemente ya advertidas, al menos de manera parcial, por el propio Dik.
} 
frente a las que disponían de un nivel suficiente de precisión y rigor cabía encontrar otras puramente impresionistas o de un poco coherente eclecticismo. Ahora bien, al margen de esto, creo que hoy día estamos en condiciones de reconocer que la práctica totalidad de las mismas intentaba dar cuenta, siquiera fuese intuitivamente, de un mismo fenómeno: la correlación entre las propiedades formales de los constituyentes oracionales y su posición relativa en una presunta jerarquía argumental dentro de la predicación. Ilustraré tal idea con unos sencillos ejemplos tomados del latín:

\section{(1) a) Mater currit.}

'La madre corre'

b) Mater cquos videt.

'La madre ve los caballos'

c) Mater puellis equos donavit.

'La madre regaló los caballos a las niñas'

Estos ejemplos muestran respectivamente predicaciones de uno, dos y tres argumentos. Si se parte de la idea de que la función sintáctica más importante y necesaria es la de sujeto ${ }^{5}$, habrá que concluir que dicha función es la desempeñada por el único argumento ('mater') de la predicación monádica representada por (1a). A partir de aquí, la función sujeto de las predicaciones diádicas (1b) y triádicas (1c) se asigna analógicamente a aquel argumento que muestra las mismas características formalies que el argumento de la predicación monádica. Para la segunda función en importancia (objeto o complemento directo) se procede de una manera similar. Primcro se asigna tal función al argumento que no es sujeto en la predicación diádica, y que, en el cjemplo (lb) es 'equos'. Y la misma función será atribuida al argumento formalmente análogo de las predicaciones triádicas como (1c). Por último, la tercera función de la jerarquía (complemento indirecto) es asignada paradigmáticamente al tercer y último argumento de las oraciones ejemplificadas por (lc). Las tres funciones sintácticas mencionadas son las consideradas fundamentales por la tradición gramatical. Al margen de ellas sólo quedan algunos casos especiales (básicamente, los complementos que no dependen del verbo, el atributo de las oraciones copulativas y el complemento agente de las pasivas) y, sobre todo, la heterogénea etiqueta del complemento circunstancial; una especie de 'cajón de sastre' en el que permanecen arrinconados todos los constituyentes que, con más o menos acierto, son tenidos por términos adicionales (es decir, no argumentales) de la predicación.

\footnotetext{
${ }^{5}$ Baste recordar que la gramática tradicional, y no pocas corrientes lingiísticas contcmporáneas, sitúan al sujeto en pic de igualdad respecto del predicado.
} 
La concepción tradicional de las funciones sintácticas, aunque responde a una indudable sensibilidad hacia los vínculos relacionales que mantienen los constituyentes de la oración, deja muchas incógnitas sin resolver y, de hecho, se revela como muy poco operativa de cara a la formulación de una teoría general con aspiraciones de alcanzar una auténtica validez interlingüística. Al margen de otros posibles reparos, de dudosa justificación ${ }^{6}$, se puede advertir un evidente riesgo de circularidad a la hora de determinar el papel que desempeñan las principales funciones en el seno de las construcciones sintácticas. Así, el sujeto es presentado primariamente como el término oracional de presencia obligada en oraciones personales, pero que está ausente en las impersonales; paralelamente, el objeto se entiende como un término exigido en las oraciones transitivas, y 'vetado' en las intransitivas. La circularidad se produce cuando, como suele ser habitual, se define el carácter personal o impersonal de la oración en virtud de la presencia o ausencia de sujeto, y la transitividad o intransitividad en virtud de la presencia o ausencia de objeto $^{7}$. Otro grave problema reside en el hecho de que la caracterización tradicional de las funciones se ve sometida en la práctica a fluctuaciones muy altas al pasar de un idioma a otro. Así, en los ejemplos latinos anteriores, el rasgo formal más relevante es sin duda la variación casual del nombre (nominativo, acusativo, dativo, ctc.). Pero, obviamente, dicho rasgo no es trasplantable a aquellas lenguas que carecen de morfología declinativa. En ellas es preciso apelar a otros rasgos formales tales como la concordancia, el uso de adposiciones, los mecanismos de pronominalización y/o relativización, el orden de constituyentes, etc. Rasgos que normalmente no actúan de manera aislada, sino por medio de una combinatoria de varios de $\operatorname{cllos}^{8}$. De ahí que las pautas formales que rigen las funciones sintácticas en una lengua como el danés (que carece tanto de declinaciones como de concordancia nombre-verbo) son sustancialmente distintas de las que lo hacen en latín, gricgo, cle. Y cso sin salimos siquiera del restringido ámbito de la familia

\footnotetext{
"Por cjemplo, se puede alegar que la concepción tradicional de las funciones sintácticas es válida sólo para las lenguas nominativas, mientras que resulta incapaz de atender los datos ofrecidos por las lenguas activas y crgativas. Ahora bien, a esto cabría responder, por un lado, que la linguiística moderna tampoco ha explicaclo todavía de modo totalmente satisfactorio el complejo fenómeno de la ergatividad, y, por otro, que todas las lenguas de nuestro entorno geográfico y cultural (probablemente con la única excepción del vasco) son nominativas, por lo que la gramática tradicional no tuvo acceso realmente a datos procedentes de otros lipos de knguas.

${ }^{7}$ Para el alcance de esta objeción son irrelevantes cuestiones tales como si las oracioncs impersonales disponen o no de un 'sujeto clidido', o si la transitividad es una propiedad del verbo o de la construcción sintácticil.

${ }^{8}$ Como es bien sabido, en latín las marcas casuales se ven coadyuvadas por la concordancia nombreverbo y por las preposiciones; cstos dos últimos rasgos, junto con, al menos, la pronominalización y el orden de constituyentes, intervienen en las lenguas romances; etc. Al menos hasta donde yo tengo noticia, no existe ninguna lenguá en la que la asignación de funciones sintácticas (en el sentido tradicional del término) se encuentre articulada en torno a un único procedimiento formal.
} 
lingüística indoeuropea. De hecho, cabe incluso preguntarse si, en términos estrictamente sintácticos (sin apelar a la semántica), lo que llamamos sujeto en danés responde a la entidad homónima del latín o el español.

Se desprende claramente que, partiendo de una concepción como la descrita, no pueden ser fijadas de antemano las propiedades gramaticales que han de ser tenidas en cuenta a la hora de proceder a la asignación de funciones sintácticas. Antes al contrario, tales propiedades son seleccionadas ad hoc en virtud de los rasgos particulares de cada lengua. Para la gramática tradicional esto no supuso, en la práctica, ningún inconveniente de especial envergadura. Los tratados de filiación racionalista? superaban este escollo apelando a argumentos lógicos y nocionales que 'reponían' en última instancia la unidad interlingüística de las notaciones funcionales, al margen de su diversidad formal aparente (cf. Chevalier, 1968). En cuanto a la gramática escolar decimonónica, su interés inmediato por la norma idiomática contribuía a que las funciones sintácticas fueran definidas y manejadas sólo con una finalidad instrumental, en virtud de las condiciones propias de la lengua considerada en cada caso y sin indagar a fondo en el alcance de sus implicaciones teóricas (cf. Chervel, 1977). El estructuralismo clásico tampoco sintió la neccsidad, en este aspecto, de cuestionar a fondo la doctrina que había heredado. Sus principales representantes (por ejemplo, Hjelmsev, 1928: 254-274), fieles al principio de inmanencia ${ }^{10}$, se mostraron en general bastante escépticos tanto ante los universales no formales como ante las generalizaciones de vasto alcance interlingüístico. Por eso, resultaba perfectamente acorde con sus postulados acometer el cstudio de las correspondencias entre forma y función sólo en el marco de un idioma concreto, a partir de la asunción de que tales correspondencias formaban parte de la singularidad inherente a cada sistema intralinguiístico. Bajo tales supuestos, toda la doctrina sintáctica del período anterior, y con ella también la relativa a las funciones, se mantenía esencialmente vigente ${ }^{11}$. A lo sumo, el estructuralismo dotó a la actividad gramatical de unos soportes teóricos y metodológicos más refinados, pero conservó un objeto de estudio y unas directrices muy semejantes a las de enfoques precedentes. Para el caso del español, un buen ejemplo de lo dicho puede detectarse al estudiar la labor, por otro lado encomiable, desarrollada por Emilio Alarcos Llorach. La teoría de las funciones sintácticas que

\footnotetext{
9 Las balses teóricas y terminológicas de la notación funcional se remontan, cuando menos, a los Modistate y los lógicos medicvales. Sin embargo, su uso como moneda común del análisis gramatical no se consolida sino varios siglos más tarde.

${ }^{10}$ Principio que sigue contando con importantes defensores. En la lingüística hispánica merece ser citado al respecto Salvador Gutiérez Ordóñez (1983: 77 y s.).

11 Como muy bien ha puesto de relieve Juan Martínez Marín (1988: 11 y s.), frente a los indudables progresos del estructuralismo en los terrenos fonológico y morfológico, la sintaxis estructural ha tenido una suerte bien distinta, al menos por lo que se refiere a la lingüistica española.
} 
expone Alarcos (1968) presenta indiscutibles coincidencias con la que ya habían consagrado las gramáticas de la RAE (1920: 183-222) ${ }^{12}$ y Rodolfo Lenz (1920: 99113), cntre otras, a principios del siglo XX. Las modificaciones introducidas responden más a reajustes técnicos que a un verdadero cambio de planteamiento: se pulen y clarifican las definiciones y los procedimientos de análisis, para eliminar de ellos cualquier posible 'desviación' logicista o psicologista; se propone una nueva terminología, que Alarcos considera más ajustada ${ }^{13}$; y poco más. Y, por supuesto, tanto la nómina de funciones como sus mecanismos de asignación están formulados expresamente para la gramática del español y responden a la idiosincrasia idiomática de esta lengua. El hecho de que tal formulación sea aplicable a otros idiomas es algo que no se descarta a priori, pero que tampoco se persigue ni forma parte de sus objetivos.

La actitud descrita a propósito de la gramática tradicional y del estructuralismo cmpicza a cuestionarse seriamente cuando, en fechas aún relativamente recientes, los cstudios gramaticales sufren un profundo giro que conlleva, entre otros cambios de gran calado, tomar en consideración los aspectos paradigmáticos en el estudio de la sintaxis y pasar a concebir la gramática como una teoría de la competencia. En cste nucvo contexto científico la doctrina clásica de las funciones sintácticas es pucsta en tela de juicio, cuando no totalmente preterida. Así, Chomsky (1965: 77), de acuerdo con la línea seguida por la lingüística norteamericana anterior, llegará a manifestar que la información funcional es redundante y que, por tanto, no tiene por qué ser añadida a las reglas de rescritura que subcategorizan los constituyentes oracionales $^{14}$. En Europa, la Escuela de Leipzig optó, durante varios años, por analizar las valencias sintácticas atendiendo únicamente a los rasgos categoriales y distribucionales de los complementos. Esta postura, justificada por Helbig (1968) sobre la idca de que cl concepto de función resulta muy poco operativo en la lingüística moderna, supuso en el plano teórico un abandono de las funciones sintagmáticas oracionales como elementos primitivos de la gramática de

\footnotetext{
12 Mancjo esta edición, si bien es cierto que las modificaciones en profundidad de los planteamientos sintácticos de la RAE se enctientran ya en la anterior, de 1917.

${ }^{13}$ Y que apenas ha tenido implantación, salvo por lo que se refiere a la denominación suplemento aplicadal al complemento preposicional regido.

${ }^{14}$ Por supuesto, a to largo de su cvolución posterior el modelo chomskyano se vio obligado a introducir informaciones relacionales que son (aunque no se les dé claramente ese nombre) funciones. En cualquicr casso, lo que me interesa señalar aquí es que Chomsky, al preferir una notación categorial $\left(\mathrm{SN}_{3}, \mathrm{SN}_{2}\right.$, $S P r e p, c t c$.) en lugar de una funcional (sujeto, objeto, complemento indirecto, etc.) se mueve guiado en buena medida por las características idiomáticas del inglés, en donde la estructura argumental de la predicación viene señalada principalmente por el orden de constituyentes (indicado por los subíndices de cada $\mathrm{SN}$ ) y por las preposiciones. Por tanto, este tipo de notación (que posteriormente fue abandonada) ni dispone de validez universal ni supera los procedimientos de análisis sintagmático de la gramática tradicional y el cstructuralismo.
} 
dependencias, $y$, en el plano de la lingüística aplicada, el que, desgraciadamente, tales funciones no hayan sido tenidas en cuenta en los principales diccionarios de valencias confeccionados por seguidores de esta escuela.

A pesar de la pujanza que a finales de los sesenta y principios de los setenta mostraban las tendencias contrarias a las funciones, lo cierto es que la mayor parte de la linguística cstructural europea del momento seguía proclamándose luncionalista y consideraba como un bagaje irrenunciable de la gramática la referencia a la información relacional. Ahora bien, la defensa de esta postura exigía sin duda rcvisar en profundidad la idea tradicional de función sintáctica, con el fin de acomodarla a las nuevas exigencias y condicionamientos emergentes en la teoría lingüística. En esta línea, las propuestas de Martinet (1960) y de la moderna Escuela de Praga ofrecían argumentos útiles, pero en cierto modo insulicientes. Con toda probabilidad fue más relevante la introducción en el análisis gramatical de las relaciones semánticas vinculadas a los constituyentes de la predicación. Tales relaciones, denominadas en las teorías formalistas 'papeles temáticos' (Gruber, 1976) o 'casos profundos' (Fillmore, 1968), responden a una razón de ser esencialmente luncional, por lo que no hay ningún impedimento para reinterpretarlas como funciones semánticas. Esto tiene una extraordinaria importancia en la medida en que permite reconocer diversos planos dentro de la organización funcional de las predicaciones y, consecuentemente, delimita mucho mejor la esfera genuina de lo sintáctico. Si es que alguna vez los hubo, a partir de ese momento no hay ya argumentos teóricos que justifiquen el que, bajo conceptos sintáclicos tales como el de 'sujeto', queden subsumidas entidades funcionales de distinta naturaleza, ya sea ésta semántica ('agente') o pragmática ('tópico'). Indudablemente, las funciones sintácticas guardan a menudo una estrecha correspondencia con tales entidades, pero siempre dentro de planos de representación claramente disjuntos y no identificables entre sí.

La clarificación conceptual y metodológica a la que me he referido dio lugar muy pronto a una seria revitalización, que llega a nuestros días, de las notaciones funcionales. Teorías gramaticales de marcada vocación funcionalista como las de Givón y Halliday son un buen testimonio de ello. Pero, llegando incluso más lejos, hay que constatar cómo desde los años setenta aparecen diversos modelos formalistas que también asumen las entidades gramaticales de carácter relacional como elementos primitivos de la teoría. Es el caso, por ejemplo, de la gramática relacional diseñada por Postal y Perlmutter (1974) y la gramática léxico-funcional liderada por Joan Bresnan (1982). A este renacer de las funciones contribuyó lambién el abandono, por parte de Chomsky, de las reglas de rescritura como procedimiento de representación de la estructura sintagmática; abandono que coincide con un período especialmente crítico y convulso dentro del generativismo. 
La aportación de Simon C. Dik en el campo de las funciones sintácticas encaja plenamente en el marco al que se ha hecho referencia. Ya a finales de los años sesenta, en el capítulo noveno de su Tesis Doctoral (cf. Dik, 1968: 162-199), intentó esbozar un modelo gramatical carente de transformaciones en el que las entidades funcionales (en aquel momento entendidas aún en términos exclusivamente sintácticos) se mostrasen compatibles con algunas de las formalizaciones introducidas por Chomsky. Ahora bien, será en la primera versión plenamente desarrollada de su modelo (Dik, 1978) donde este autor deje asentadas las grandes líneas de su concepción de las funciones. Dik postula entonces que en la gramática de toda lengua existen tres niveles de asignación gramatical, introducidos paulatinamente ${ }^{15}$. El primero de ellos, de carácter semántico, es universal y primitivo para la teoría. El segundo nivel es el sintáctico, y se manifiesta solamente cuando en una lengua se constata la existencia de lo que Dik denomina 'cambio de perspectiva'. Por último, las funciones pragmáticas, situadas en un tercer nivel, dan cuenta (al menos en el planteamiento originario) de la estructura informativa de la oración, en la línea de las propuestas de Mathesius y otros seguidores del funcionalismo praguense.

La teoría dikeana establece que el ámbito inicial y prioritario para la organización funcional subyacente de la predicación es de naturaleza semántica. Este factor, unido además a la presencia de las funciones pragmáticas, introduce sin duda una modificación muy sustancial respecto de la doctrina tradicional. Pero hay que reconocer al mismo tiempo que tampoco constituye algo excepcional si lo comparamos con otros modelos gramaticales contemporáneos. Ahora bien, lo que sí puede ser considerado un hecho bastante singular es cómo se ha reinterpretado, bajo tales supuestos, el papel que desempeñan en la descripción gramatical las funciones sintácticas. En buena medida la clave de esta singularidad reside en que su asignación se rige por un único criterio (el 'cambio de perspectiva'). Esto hace que, como intentaré mostrar en el próximo apartado, frente al carácter 'absoluto' que mostraban en la gramática tradicional, las funciones sintácticas dispongan en la GF de un espacio mucho más relativo y mediatizado.

\section{La asignación de funciones sintácticas según la GF}

El concepto de función sintáctica tiene en la GF un alcance mucho más restringido que en la mayor parte de las teorías lingüísticas de orientación funcional. Sólo se toman en consideración dos funciones sintácticas (sujeto y objeto), destinadas a fijar respectivamente la perspectiva primaria y la perspectiva

\footnotetext{
Mediante sucesivos enriquecimientos de la estructura, no mediante transformaciones.
} 
secundaria de la oración. Es más, estas funciones sintácticas, a diferencia de las semánticas, no se entienden ni como primitivas en la teoría ni como universales Iinguísticos. Eso quiere decir que, a juicio de Dik, son perfectamente posibles (y, de hecho, bastante numerosas) las lenguas que carecen de ambas funciones sintácticas, o las que disponen de la función sintáctica sujeto pero no de la función objeto. Ahora bien, también es cierto que Dik (1989) indica expresamente que no se han documentado lenguas que, disponiendo de función objeto, carezcan al mismo tiempo de la función sujeto. De esta constatación empírica se desprende, como universal implicacional, el hecho de que, si una lengua dispone de objeto, entonces dispone necesariamente de sujeto.

La noción de perspectiva no resulta enteramente nueva, aunque hay que admitir todavía es utilizada de forma bastante intuitiva y poco precisa. Guarda cierta semejanza con conceptos tales como la familiaridad de Ertel (1977), la empatía de Kuno (1987) e incluso con la puesta de relieve de la que habla Tesnière (1959: 129) al tratar la construcción de la frase alemana. Sin embargo, la noción de perspectiva de la GF recibe un uso bastante más limitado, dado que no hace referencia ni a la distribución lineal de los constituyentes ni a distinciones tipológicas (como las diferencias entre lenguas activas, acusativas y ergativas). Las oposiciones estructurales interpretadas como alternancia de perspectiva se reducen en síntesis a lo que, en un sentido más amplio del habitual, podríamos denominar 'variedades de diátesis'. Siewierska (1991: 78) contempla otros casos susceptibles de ser interpretados a partir de una diferencia de perspectiva (entre los que se encuentran los predicados recíprocos, las pasivas léxicas, las distinciones deícticas y anafóricas, ctc.). No es probable sin embargo que todos estos fenómenos puedan recibir una explicación satisfactoria en términos de perspectivización $y$, en cualquier caso, la GF no la ha abordado todavía de modo sistemático. Por todo ello, la perspectiva, en el sentido en que ha sido utilizada por la GF, constituye un instrumento particular, no equivalente a ninguno de los usados en otras escuelas linguísticas y difícilmente trasladable a los cánones habitualmente utilizados por cllas. Prácticamente, la deducción que se extrae es que la perspectiva se tiene en cuenta nada más que a la hora de atender las funciones sintácticas, cuya presencia en la GF viene motivada por la constatación en distintas lenguas de alternancias de voz (Hoekstra, 1984: 13). Si Dik sólo toma en consideración dos funciones sintácticas es porque únicamente se han documentado en las lenguas del mundo dos procesos claramente reconocibles como alternancia de diátesis. La función sujeto está asociada a la pasividad y procedimientos gramaticales análogos. La función objeto se identifica con el fenómeno que la lingüística anglosajona ha dado en doniminar 'ascensión de dativo' (dative raising). Si tomamos como ejemplo el español, se observa claramente que dispone de función sujeto, pues tiene un mecanismo de alternancia diatética de pasividad. En cambio, habría que reconocer 
que carece de la función objeto, dado que la ascensión de dativo no forma parte de las posibilidades gramaticales de nuestra lengua. En cambio, el inglés sí dispone de ambas funciones sintácticas. Las oraciones recogidas a continuación lo demuestran fehacientemente:

(2) a) La policía $a_{\text {suj }}$ detuvo al estafador.

b) El estafador $r_{\text {suj }}$ fue detenido por la policía.

(3) a) Lucía dio un beso(obi?) a su madre.

b) "Lucía dio su madre (ohji? $_{\text {in }}$ un beso.

(4) a) Mary $y_{\mathrm{sul}}$ lent a kite to her brother.

'Mary prestó una cometa a su hermano'

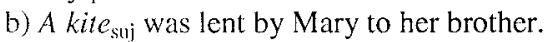

'Una cometa fue prestada por Mary a su hermano'

c) Her brother $r_{\text {suj }}$ was lent a kite by Mary.

'A su hermano le prestó una cometa Mary'

(5) a) Mary lent $a$ kite bbj $_{j}$ to her brother.

'Mary prestó una cometa a su hermano'

b) Mary lent her brother ${ }_{\text {ohj }}$ a kite.

'Mary prestó a su hermano una cometa' ${ }^{16}$

La regulación de la asignación de las funciones sintácticas en la GF viene detcrminada por una Jerarquía de Funciones Semánticas (en adelante, JFS) de carácter universal. La JFS se formula actualmente en los siguientes términos:

(6)

\begin{tabular}{|c|c|c|c|c|c|c|c|c|c|c|c|c|c|}
\hline & $\mathrm{Ag}$ & & Mel & & Rec & & Ben & & Inst & & Ubic & & Tiemp \\
\hline & + & $>$ & + & $>$ & + & $>$ & + & $>$ & + & $>$ & + & $>$ & + \\
\hline ВJETO & & & & $>$ & + & $>$ & + & $>$ & + & $>$ & + & $>$ & + \\
\hline
\end{tabular}

La JFS señala que el principal candidato para recibir la función sintáctica sujeto es el constiluyente con función semántica agente. Las posibilidades descienden según se va hacia la derecha en la escala, hasta las funciones semánticas ubicación y tiempo. De ese modo, se entiende que la coincidencia de la función semántica agente y la función sintáctica sujeto en un mismo constituyente oracional da lugar a

\footnotetext{
16) Repárese en que la traducciones literales de (4c) y de (5b) serian, respectivamente: '*su hermano fue prestado una comcta por Mary' y '"Mary prestó su hermano una cometa'. Ambas son agramaticales porque los procesos de alternancia de diátesis que dan lugar a sus correlatos ingleses no están permitidos en español. Las traducciones que se recogen en el cuerpo del texto, y que intentan adecuarse al sentido del original, presentan un cambio en el orden de constituyentes que debería ser interpretado en función de la estructura informativa. En términos de la GF, eso quiere decir que lo que en inglés se expresa por medio de la asignación de las funciones sintácticas, en español se hace en el ámbito de las funciones pragmáticas.
} 
una construcción no marcada, mientras que las demás posibilidades dan lugar a construcciones marcadas en mayor o menor medida, según su lugar en la JFS. Algo similar puede decirse del objeto, con la diferencia de que en este caso el principal candidato es el constituyente con función meta, toda vez que el agente tiene totalmente vedado el recibir la asignación de dicha función sintáctica. Esta jerarquía no llega a completarse prácticamente en ninguna lengua. Ello se debe a que en cada una existe un 'punto de corte' dentro de la JFS, más allá del cual resulta inviable asignar las funciones sintácticas. El inglés, por ejemplo, presenta su punto de corte detrás del receptor, lo que permite tres posibilidades de alternancia de sujeto y dos para la alternancia de objeto (cf. los ejemplos señalados anteriormente con los números 4 y 5). El español, por su parte, presenta su punto de corte tras la función meta, por lo que dispone solamente de dos posibilidades alternativas para la asignación de sujeto, y carece de alternancia diatética para la función objeto. Por otro lado, conviene señalar que, aunque en español y en inglés el punto de corte de la función sujeto y de la función objeto están situados en el mismo lugar de la JFS, esto no ocurre así en otros casos. En numerosas lenguas (holandés, japonés, etc.) no existe simetría entre el punto de corte de la función sujeto y el de la función objeto.

Tal vez resulte chocante que se diga que el español es una lengua que carece de la función objeto. Sin embargo, desde el punto de vista de la GF no puede admitirse otra cosa. Claro está que conviene recordar en todo momento que, a pesar de la coincidencia terminológica, estamos hablando aquí de algo muy distinto de lo que comúnmente se llama objeto directo. Aunque sin duda es difícil renunciar a la concepción clásica de las funciones sintácticas, que está muy interiorizada en nuestro entorno y cuenta con el peso de la tradición, no deben evaluarse bajo su prisma las conclusiones extraídas bajo los presupuestos, sustancialmente distintos, de la GF.

La relación gramatical que tradicionalmente se identificaba con el objeto directo ('entidad afectada o efectuada por una acción, proceso o posición') es interpretada en el marco teórico de la GF —a mi juicio con total acierto- en términos semánticos; se corresponde por tanto con la función semántica denominada meta. En español (pero no así en inglés, como se ha visto por los ejemplos anteriores) se confunden por entero los rasgos gramaticales de la función semántica meta y de la función sintáctica objeto. De ahí que se pueda hablar con propiedad de inexistencia de la función objeto, ya que resulta totalmente superflua y no añade nada a la caracterización semántica que, en la GF, es previa a la sintáctica. Mantener la función objeto e identificarla en la práctica siempre con la función meta sería una decisión viable, pero totalmente fútil. Por eso, y haciendo uso de la 'navaja de Ockham', resulta mucho más ajustado metodológicamente prescindir por completo de ella en los análisis dedicados a nuestra lengua. 


\section{Asignación de objeto y cambio de marca en las lenguas bantúes}

La teoría de la JFS, desarrollada por Simon C. Dik, ha demostrado su amplia capacidad explicativa a la hora de ser contrastada con los hechos empíricos documentados en una gran cantidad de lenguas. No obstante, hay que reconocer que también se ha encontrado con algunas dificultades de notable envergadura. En concreto, cl mecanismo de distribución de marcas de casos de las lenguas ergativas (en las que el argumento de las predicaciones intransitivas se corresponde morlológicamente con el segundo argumento de las predicaciones transitivas) se revela totalmente incompatible con la JFS. Como vía de solución, Dik asume la ya centenaria hipótesis de Hugo Schuchardt, según la cual la ergatividad procede diacrónicamente de una generalización de la voz pasiva ${ }^{17}$. De acuerdo con esto, las lenguas ergativas serían originariamente nominativas, pero con una voz pasiva dotada de una gran frecuencia de uso. Con el tiempo, la voz activa, en las construcciones transitivas, fue perdiendo vigencia hasta quedar totalmente obsoleta, al ser sustituida completamente por la pasiva. Este proceso diacrónico, que Dik incluye dentro de un fenómeno general de 'cambio de marca', nos llevaría en las lenguas ergativas a una situación en la que las oraciones intransitivas procederían de una construcción activa, y las transitivas de una antigua voz pasiva en donde el caso crgativo del primer argumento procedería de un complemento agente originario $^{18}$. Esta hipótesis, aunque ciertamente no resuelve todos los problemas que suscitan las lenguas ergativas, especialmente desde el punto de vista sincrónico, sí permite al menos establecer una primera base argumentativa para acometer la explicación de sus propiedades gramaticales más características.

Cabe preguntarse ahora si el proceso de cambio de marca aludido se verifica únicamente en la asignación de sujeto o si, por el contrario, existe un proceso análogo por lo que respecta a la función sintáctica objeto. Dicho en otros términos, ¿existen lenguas naturales caracterizadas por una 'ergatividad de objeto', fruto de un proceso diacrónico de generalización de la ascensión de dativo? Todo hace indicar que Simon C. Dik (1997, I: 282-284) opta por una respuesta afirmativa a csia prcgunta. La explicación que ofrece para el mecanismo de asignación de objeto

\footnotetext{
${ }^{17}$ Dik cita al respecto un artículo de Schuchardt (1895) sobre las lenguas caucásicas. Debe señalarse, en cualquier caso, que dicha hipótesis ya fue formulada por el gran filólogo austriaco algunos años antes, a partir de una investigación acerca de la lengua vasca (cf. Schuchardt, 1893).

${ }^{18}$ Un argumento a favor de este planteamiento viene dado por el hecho de que la gran mayoría de las lenguas crgativas carecen de voz pasiva. Las escasas excepciones a este aserto (tales como el esquimal de Groenlandiat) parecen responder a procesos de evolución relativamente recientes, como fruto de un posterior reajuste del sistema gramatical.
} 
en las lenguas del grupo bantú va encaminada claramente en esta dirección. Ahora bien, la teoría del cambio de marca no siempre resulta plenamente satisfactoria para el análisis de las propiedades gramaticales de las estructuras transitivas de estas lenguas. Mientras que el comportamiento de algunas de cllas parece responder de mancra bastante ajustada a las previsiones de la misma, en otros casos surgen diversas dificultades que obligan a tomar en consideración otras posibilidades.

A la hora de estudiar los procesos de asignación de objeto en algunas de las lenguas bantúes hay que hacer una distinción entre dos grupos. Por un lado, nos encontramos con lenguas como el chona o el chimuini, en las que parece verificarse la existencia de un proceso de cambio de marca que ha conducido a una ergatividad de objeto. Por otra parte, un segundo grupo, en el que figuran el quiñaruanda y el suahelí, presenta unos mecanismos de transitividad mucho más complejos, cuyo análisis requiere tener en cuenta otros factores.

Las estructuras transitivas del chona y del chimuini se caracterizan porque, cuando el predicado dispone únicamente de dos argumentos, agente y meta, es este último el que recoge los rasgos formales de expresión vinculados a la función objeto. Ahora bien, cuando en la oración aparece un tercer argumento con función semántica receptor, es éste, y no el término meta, el que debe recibir, obligatoriamente, tales rasgos gramaticales. Al margen del meta y el receptor, ningún otro término va asociado a unas marcas análogas, por lo que cabe concluir que en estas lenguas el punto de corte dentro de la JFS, para la función objeto, se halla situado tras el receptor. Este comportamiento encaja perfectamente con la teoría dikeana del cambio de marca, puesto que puede ser explicado como consecuencia de una generalización de la ascensión de dativo, análoga a la generalización de la pasiva característica de la ergatividad de sujeto. De dicho proceso diacrónico ha derivado, en sincronía, una situación en la que ya no existe realmente ningún procedimiento que permita el cambio de perspectiva; para una misma predicación, solo existe una única posibilidad de asignación funcional. El que tal asignación se asocie a una u otra función semántica (meta o receptor) no depende tanto de la construcción sintáctica como de la naturaleza léxico-semántica de la predicación. Las predicaciones triádicas que indiquen transferencia marcarán de modo específico el término receptor, mientras que el resto de predicaciones marcarán el término meta. Así pues, y según los principios teóricos de la GF, el chona y el chimuini carecen, en puridad, de función objeto, toda vez que no disponen de alternancia de perspectiva. Esto también concuerda análogamente con los datos de la mayor parte de las lenguas ergativas que, al no disponer en sincronía de construcciones pasivas, carecen de una función sujeto propiamente dicha.

El fenómeno aquí descrito no es exclusivo de estas lenguas del grupo bantú, que no constituyen al respecto ninguna excepcionalidad tipológica. Aunque Dik no lo recoja explícitamente, creo que la generalización de la ascensión de dativo está en 
la base de algunos hechos gramaticales constatados al menos en ciertas lenguas uto-aztccas, como el huichol (cf. Comrie, 1982: 102-105), y mayas (cf. Norman, 1978). En todas cllas, las semejanzas formales entre el término meta de las predicaciones diádicas y el receptor de las triádicas habría que buscarlas, no ya en una coincidencia de función sintáctica, sino más bien en el hecho de que ambos aparczcan como segundo argumento de sus respectivas predicaciones ${ }^{19}$.

En quiñaruanda y en suahelí, a diferencia de lo que ocurre en las lenguas mencionadas anteriormente, sí se perciben diversas posibilidades sintácticas de cambio de perspectiva dentro de una misma predicación. Cabe en las mismas distinguir tres supuestos básicos:

(A) Cuando sc trata de predicaciones que carecen de términos con funciones scmánticas receptor y beneficiario, entonces cabe encontrar una alternancia, cn la asignación de la función objeto, entre el término meta y diversos términos satélites (instrumento, ubicación, modo, etc.). Así puede observarse en el siguiente ejemplo en quiñaruanda, que tomo de Siewierska (1991: 98):

(7) a) umugóre a-ra-andik-a ibarúwa n'i-ikarámu mujer $3^{\mathrm{a}}$ pers-pres-escribir-indic carta con-pluma

b) umugóre a-ra-andik-iish-a ibarúwa ikarámu mujer $3^{\mathrm{a}} \mathrm{pers}$-pres-escribir-instr-indic carta pluma

La traducción al español de ambas oraciones es la misma ('la mujer escribe una carta con una pluma'), pero sus diferencias sintácticas hacen pensar en un cambio de perspectiva que la traducción no es capaz de recoger. En (7a) el instrumento (ikarámu) va acompañado por un prefijo que señala su condición de satélite. Por tanto, en dicha oración la función objeto recae sobre el término meta (ibarúwa). En (7b) tanto el meta como el instrumento se hayan exentos de marcas formales de oblicuidad, pero sí aparece un afijo verbal (-iish-) de valor instrumental, interpretable por tanto como una marca de diátesis que liga la función objeto al término instrumento.

(B) Cuando cn una predicación aparece un término receptor, y no hay en la misma un beneficiario, entonces la función objeto recae forzosamente sobre el receptor, sin posibilidad de alternancia y al margen de cuales sean los demás términos de la predicación.

(C) Cuando en la predicación aparece un beneficiario, entonces la función objcto recac forzosamente sobre el mismo, sin posibilidad de alternancia y al margen de cuales sean los demás términos de la predicación.

Los supuestos (A) y (B) no plantean, en principio, especiales complicaciones para la GF. La asignación obligatoria de la función objeto al receptor sería una

\footnotetext{
${ }^{19}$ Sobre jos conceptos de primer, segundo y tercer argumento en la GF, cf. Dik (1989: 100 y ss.).
} 
consecuencia de un cambio de marca, que convertiría esta posibilidad en la opción menos marcada y, por tanto, preferible. Sólo ante la ausencia de receptor las demás funciones semánticas contempladas en la JFS tendrían la posibilidad de recibir, y de modo alternativo, la función objeto. Ahora bien, el supuesto (C) dista mucho de ser atendido adecuadamente por la teoría del cambio de marca. Mientras que esta teoría prevé que la asignación prioritaria de la función objeto se traslada un grado en la JFS (de meta a receptor), el supuesto (C) sitúa la opción prioritaria del objeto en el beneficiario, dos grados por debajo en la JFS. Apoyándose en datos de Gary y Keenan (1977), Dik (1978: 149) resuelve esta dificultad, para el caso del quiñaruanda, alegando que en dicha lengua las funciones semánticas receptor y beneliciario sc encuentran totalmente neutralizadas, y ocupan un único espacio en la JFS ${ }^{20}$. Ahora bien, tal explicación resulta ineficaz para el suahelí, donde ambas funciones inciden de modo muy distinto en la configuración de la forma verbal. Así puede comprobarse en los siguientes ejemplos ${ }^{21}$ :

(8) a) Hamisi a-li-pik-a samaki

Hamisi $3^{a}$ pers-pret-cocinar-indic pescado

'Hamisi cocinó pescado'

b) Hamisi a-li-m-pik-i-a m-toto samaki

Hamisi $3^{a}$ pers-pret-él-cocinar-ben-indic sing-niño pescado

'Hamisi cocinó pescado para el niño'

c) Hamisi a-li-m-p-a m-toto samaki

Hamisi $3^{a}$ pers-pret-él-dar-indic sing-niño pescado

'Hamisi dio pescado al niño'

La presencia en el verbo de (8b) y (8c) del afijo de carácter pronominal (-m-) establece la concordancia entre el verbo y el término beneficiario o receptor (mtoto), y constituye para Dik la prueba formal de que son estas funciones y no la meta (samaki) las que reciben la asignación de objeto, de forma obligatoria, en sus respectivas oraciones. La presencia del beneficiario va asociada además a la aparición de un nuevo afijo (-i-), que el receptor no produce. Por ello no puede postularse en este caso una neutralización de ambas funciones. Ante esta dificultad, Dik (1989: 241) sugiere que las estructuras representadas por la oración (8c) requieren un nuevo análisis, en el que el supuesto receptor (mtoto), ha de ser

\footnotetext{
20 Sin embargo, Kimenyi (1988), partiendo de los postulados teóricos de la gramática relacional, argumenta en contra de esta supuesta neutralización, y aboga por la existencia de una múltiple función objeto en quiñaruanda.

${ }^{21}$ Los ejemplos en suahelí recogidos en este trabajo han sido elaborados básicamente a partir de los dalos ofrecidos por Ashton (1944) y Van Pelt (1985). Su gramaticalidad ha sido contrastada con el Doctor Mbuyi Kabunda, del Colegio Santa María de África, de Madrid, a quien agradezco profundamente su colaboración.
} 
interpretado en realidad como término meta, mientras que la supuesta función meta (samaki) pasaría a ser considerada como un término satélite. Esta asunción, a primera visia rebuscada y contraria a los propios principios de la GF, no lo es en absoluto si se tienen en cuenta ciertos fenómenos similares detectados en los predicados que denotan 'transferencia' en las lenguas occidentales más conocidas. Véase si no el comportamiento del verbo inglés SUPPLY en estos ejemplos tomados de Siewierska (1991; 94):

(9) a) Pakistan supplies weapons mei $_{\text {to }}$ to Afganistan rec $_{\text {Pac }}$

'Pakistán proporciona armas a Afganistán'

b) Pakistan supplies Afganistan mel $_{\text {with }}$ weapons instr $_{\text {it }}$

'Pakistán abastece a Afganistán de armas'

Lo que se observa aquí es que este verbo puede dar lugar a una estructura triádica o bien a una estructura diádica ${ }^{22}$. En este último caso, la entidad a la que se dirige la transferencia cs codificada lingüísticamente como 'afectada' por el proceso de transferencia, por lo que actúa como término meta. La entidad transferida, por su parte, no se contempla como argumento del marco predicativo. Su presencia en la predicación se produce, bien de manera implícita (a través del propio contenido léxico del predicado), bien mediante una expansión con un complemento satélite con función instrumento, como ocurre en (9b). En opinión de Dik, lo que ocurre en suahelí es que los predicados de transferencia rigen únicamente estructuras análogas a la de (9b), con lo que la función receptor no estaría contemplada verdaderamente en ningún marco predicativo del léxico suahelí. Por eso, al producirse cl cambio de marca en esta lengua, la asignación prioritaria de objeto habría pasado en la JFS directamente de meta a beneficiario, ya que la posición del receptor resultaría irrelevante para la lengua que estamos considerando.

De acuerdo con todo lo anterior, cabe reelaborar los tres supuestos antes consignados con las modificaciones que, según Dik, permitirían la adecuación de la tcoría del cambio de marca a los procedimientos gramaticales del suahelí.

(A’) En las predicaciones diádicas, la función objeto se asigna al término meta, que actúa como segundo argumento y concuerda con un afijo pronominal del verbo.

(10) Ni-me-vi-l-a vi-azi

1 "pers-pret-plur-comer-indic plur-patata

'He comido patatas'

\footnotetext{
22 Esta dualidad de estructura se explica a partir del componente de base, por medio de reglas de formación de predicados. No se trata, consecuentemente, ni de un proceso transformacional ni de una alternancia de perspecliva.
} 
En caso de que la predicación vaya complementada por ciertos términos satélites (instrumento, ubicación, etc.), estos pueden recibir la asignación de objeto, en construcciones marcadas, por medio de procedimientos de cambio de diátesis.

(B') En las predicaciones que denotan transferencia, la entidad receptora es codificadal, según Dik, como término meta. Ocupará entonces la segunda posición argumental y recibirá la asignación de objeto (siempre y cuando no exista en la misma predicación un término beneficiario). Además, este término concuerda con cl alijo pronominal del verbo, el cual no sufre modificación de diátesis. Por su parte, la cntidad transferida queda codificada como término satélite, externa a la predicación nuclcar.

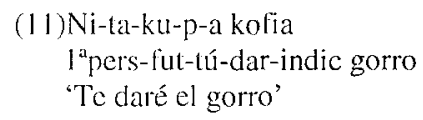

(C') En las predicaciones que disponen de un beneficiario, éste ocupa la segunda posición argumental, debido a un proceso de cambio de marca, y recibe obligatoriamente la asignación de objeto. Ello provoca, además de la aparición del alijo pronominal correspondiente, un cambio en la diátesis del verbo, marcada por el alijo aplicativo -i-:

\section{(12)Anyesi a-li-tu-pik-i-a wali \\ Anyesi $3^{\mathrm{a}}$ pers-pret-nosotros-cocinar-ben-indic arroz \\ 'Anyesi nos cocinó arroz'}

\section{Reanálisis del afijo aplicativo -i- del suahelí}

El análisis dikeano de la asignación de objeto en suahelí no carece de atractivos, a pesar de que, como advierte Siewierska (1991: 74), implica un cierto grado de manipulación respecto de los principios previamente asumidos dentro de la GF. En cualquicr caso, todas las teorías lingüísticas actuales encuentran enormes dificultades para explicar los complejos mecanismos con los que se manifiesta la transitividad en las lenguas bantúes, y hasta el momento éste es tal vez el único intento de afrontarlos sin apelar a la incorporación, a menudo incontrolada, de nuevas lunciones sintácticas (tales como 'objeto primario', 'objeto secundario', ctc.). Lamentablemente, creo que la hipótesis de Dik sigue sin ofrecer una solución apropiada, pues pueden esgrimirse multitud de contraejemplos que la ponen en tela de juicio. A mi entender, esto no implica una insuficiencia de la GF acerca de la asignación de lunciones sintácticas, pero sí obliga a buscar otras propuestas 
alternativas que, sin alterar los fundamentos básicos de la teoría, se revelen como más ajustadas a los datos disponibles.

Uno de los aspectos más débiles de la hipótesis de Dik radica en la interpretación del afijo verbal -i-. Considerarlo como marca de asignación de objeto al beneficiario choca con el hecho de que también aparece cuando éste es el sujeto de una oración pasiva:

\section{(13)M-toto a-li-pik-i-w-a samaki na mama sing-niño $3^{a}$ pers-pret-cocinar-ben-pas-ind pescado por madre 'Al niño lc cocinó pescado la madre ${ }^{, 23}$}

Esto hace pensar que dicho afijo no es en realidad una marca de objeto, sino un índice de la presencia de la función semántica beneficiario, al margen de la función sintáctica que descmpeñe. Por tanto, su funcionamiento habría de ser explicado en cl componente de base, dentro de las reglas de formación de predicados, y no en el plano sintáctico de representación.

Dik, pese a advertir esta circunstancia, optó siempre por mantener el análisis del alijo -i- como marca de objeto. La marea de asignación de sujeto al beneficiario estaría conformada cntonces por la combinación de dicho afijo con la marca de pasiva (-w-). Ello queda sintetizado en el siguiente esquema (cf. Dik, 1997, I: 380), en el que se recogen las marcas de asignación de funciones sintácticas para el primer argumento de la predicación $\left(\mathrm{A}^{\prime}\right)$, para el término meta y para el beneficiario:

$\begin{array}{lccc} & A^{1} & \text { META } & \text { BENEFICIARIO } \\ \text { SUJETO } & \varnothing & -w- & -i-w- \\ \text { OBJETO } & & \varnothing & -i-\end{array}$

Esta solución, aunque factible, me parece excesivamente artificiosa. La aparición del afijo -i-, según el esquema anterior, puede estar motivada por dos factores en apariencia independientes: la asignación de objeto y la asignación de sujecto, cuando su identificación como marca de aparición de un término bencliciario simplificaría la descripción y aportaría un tratamiento unificado de este alijo. Paralclamente, la aparición de - w- no se entiende como marca de pasiva (es decir, 'sujeto no $\mathrm{A}^{\mathrm{l}}$ '), sino como 'asignación de sujeto a meta' y 'asignación de sujeto a beneficiario', también como hechos independientes. Asimismo, otro factor que incide especialmente en una valoración negativa del esquema (14) descansa en

\footnotetext{
${ }^{23}$ La traducción litcral scría kel niño fue cocinado pescado por la madre, que es agramatical porque ci español no admite la asignación de sujeto al beneficiario.
} 
el hecho de que es incapaz de evitar una segunda lectura, simplista y a todas luces contraintuitiva, por la cual se interpretaría - $\mathrm{i}-\mathrm{w}$ - como -iw-, convirtiendo en signo unitario lo que es una combinación sintagmática de dos unidades discretas.

Otra dificultad, y de mucha más trascendencia, está relacionada con el comportamiento de los afijos pronominales del verbo, que Dik analiza como marcas formales de la asignación de función objeto. La validez de dicho planteamiento descansa sobre las siguientes predicciones:

(15) a) Dado que para la GF sólo hay una función objeto, entonces sólo el constituyente que desempeñe dicha función podrá concordar con el verbo, mientras que los términos que carecen de función sintáctica han de quedar exentos de marca de concordancia.

b) En las predicaciones que denotan transferencia y carecen de beneficiario, es la entidad a la que se dirige la transferencia la que debe concordar con el verbo mediante un afijo pronominal, mientras que la cntidad transferida ha de quedar sin marca de concordancia, toda vez que debc funcionar como término satélite.

El cumplimiento de (15a) es imprescindible para sostener, como se hace hasta ahora, que los afijos pronominales actúan como marcas de asignación de objeto. De lo contrario, habría que considerarlos únicamente como formas pronominales de referencia cruzada que habrían de ser analizadas en un plano de representación diferente, por medio de reglas de expresión específicas. El cumplimiento de (15b) es obligado para justificar la irrelevancia en suahelí de la función semántica receptor. Pero creo estar en condiciones de señalar que tanto (15a) como (15b) son inconsistentes con los datos (cf. Van Pelt, 1985: 22). He aquí algunos ejemplos que pueden servir como muestra:

(16)a) Ni-me-li-l-a chungwa tamu

$l^{2}$ pers-pret-eso-comer-indic naranja dulce

'He comido una naranja dulce'

b) Ni-me-li-m-pat-i-a Ali chungwa tamu

1"pers-pret-eso-él-conseguir-ben-indic Alí naranja dulce

'He conseguido para Alí una naranja dulce'

c) Ni-ta-li-m-p-a Ali chungwa tamu

I pers-fut-cso-él-dar-indic Alí naranja dulce

'Le daré a Alí una naranja dulce' 
En todas estas oraciones se detecta un afijo pronominal (-li-) que concuerda en género con chungwa tamu ('naranja dulce') ${ }^{24}$. Y ello no sólo en la predicación diádica (16a), en donde ocupa necesariamente una segunda posición argumental con función scmántica meta. También se da esta circunstancia en (16b) y (16c), oraciones en las que teóricamente el segundo argumento es $A l i$ y en las que chungwa tamu no puede considerarse bajo ningún concepto el objeto de la oración. Tanto en (16b) como en (16c) hallamos un segundo prefijo pronominal (-m-), que concuerda en género (es decir, en 'clase nominal') con Ali. Todo esto va en contra de lo afirmado por (15a). Además, el análisis que postula que en (16c) el término chungwa tamu es un término satélite, mientras que el término meta es Ali (la entidad a la que se dirige la transferencia) resulta difícilmente sostenible, pues ¿cómo puede entonces el supuesto término satélite de (16c) mantener el mismo tipo de concordancia, y mediante el mismo pronombre, que el término meta de (16a) y (16b)? ¿No indica esto que chungwa tamu sigue siendo también aquí término meta, y que Ali, que en (16b) es el beneficiario, actúa en (16c) como un auténtico término con función semántica receptor? De contestarse afirmativamente esta última pregunta, ¿habría que concluir que la función receptor sí sería relevante en suahelí, en contra de la postura defendida por Simon C. Dik?

Ante las enormes dificultades e interrogantes que suscita la teoría dikeana de asignación de objeto en suahelí, creo que lo más ajustado es una hipótesis que aborde este problema desde una perspectiva sustancialmente distinta. En primer lugar, considero que los afijos verbales de concordancia no pueden ser considerados como índices de función sintáctica. Parece mucho más factible, a tenor de lo visto en los párrafos anteriores, considerarlos como producto de ciertas reglas formales de expresión, particulares de la lengua suahelí y externas a la configuración funcional de las predicaciones.

Por lo que se refiere al análisis del afijo aplicativo (-i-), creo que tampoco constituye una marca de asignación de objeto (cf. el ejemplo (13)), sino un índice de la presencia de un beneficiario como término de la predicación. Esto se explicaría, de un modo a mi juicio simple y eficaz, por medio de una regla léxica, operativa sincrónicamente, destinada a la formación de predicados derivados ${ }^{25}$, sin menoscabo de que, en su origen, esta situación haya surgido de un proceso diacrónico de cambio de marca. De igual manera, la interpretación de la asignación de sujeto al beneficiario, en el ejemplo (13) y otras oraciones análogas, se vería también sensiblemente simplificada, puesto que los afijos -i- y -w- responderían a

\footnotetext{
24 En la traducción morfológica interlineal, he traducido convencionalmente el prefijo -li- por 'eso'. Esta traducción, por supuesto, no puede reproducir la totalidad de sentido de este prefijo, que es el designador en singular de la clase 'fruto', a la que pertenece chungwa ('naranja').

${ }^{25}$ Siewierska (1991: 103 y ss.) llega a una conclusión similar al analizar los afijos instrumental (-iish-) y modal (-an-) del quiñaruanda.
} 
fenómenos situados en distintos planos de representación: el primero en el componente de base, como marca de un proceso léxico, y el segundo en el plano funcional sintáctico, como marca de cambio de diátesis para la asignación de sujeto.

Según esta propuesta, cuando un determinado predicado de la lengua suahelí va acompañado de un afijo - $\mathrm{i}$ - no significa que dicho predicado haya sufrido un cambio de diátesis, sino que ha sido objeto de una operación léxica que ha dado lugar a una nueva unidad del componente de base, caracterizada por contar entre sus complementos con un término beneficiario. Así, si tomamos como ejemplo el predicado PAT ('conseguir'), el predicado derivado correspondiente sería PATI ('conscguir [para alguien]')

De acuerdo con el formato habitual seguido por la GF a la hora de exponer las reglas de formación de predicados derivados, creo que cabe exponer la regla que nos ocupa en csta ocasión del siguiente modo:

\begin{tabular}{|c|c|}
\hline input: & $\operatorname{predicado}_{\beta}\left(x_{1}\right)\left(x_{2}\right) \ldots\left(x_{n}\right)$ \\
\hline condiciones: & $\beta=V[+$ control $]$ \\
\hline & $\left(x_{1}\right)=\left(x_{1}:\right.$ animado $\left.\left(x_{1}\right)\right)$ \\
\hline output: & $\begin{array}{l}\text { Presencia de un término }\left(x_{j}\right)_{\text {hen }} \\
\text { predicado- } j_{\beta}\left(x_{1}\right)\left(x_{2}\right)\left(x_{i}\right)_{h n} \ldots\left(x_{11}\right)\end{array}$ \\
\hline
\end{tabular}

La regla (17) señala que el punto de partida o input ${ }^{27}$ es un predicado del lexicón que puede ir complementado por ciertos términos $(x$, con distintos subíndices), en número no prefijado. Las condiciones para la aplicación de la regla señalan que el predicado debe responder a la categoría verbo y, asimismo, describir un estado de cosas controlado ${ }^{28}$. Esto último es, de acuerdo con Dik (1978: 58), un requisito semántico imprescindible para que pueda estar presente la función semántica bencficiario en una predicación. Y dicha presencia, indicada por medio del constituyente denominado convencionalmente $x_{i}$, es otra de las condiciones neccsarias para la puesta en ejecución de la regla. El carácter controlado del estado de cosas implica asimismo que el primer término argumental vinculado al

\footnotetext{
${ }^{26}$ En Ios glosarios incluidos en los manuales de Ashton (1944: 364-381) y Van Pelt (1985: 256-303) sc tona como lema de una lexía verbal la combinación de la raíz más la desinencia modo-aspectual (-a). Por mi parte, prefiero consignar en este texto sólo la raíz del verbo: PAT (y no PATA), AMK (en lugar do AMKA), etc.

${ }^{27} \mathrm{He}$ optado por no traducir los términos ingleses input y output por considerarlos suficientemente introducidos en la bibliografía del español y, por tanto, más fácilmente reconocibles que algunas de las traducciones que en ocasiones se han propuesto (tales como 'aducto' y 'educto').

${ }^{28}$ Un estado de cosas es controlado si su primer argumento es una entidad tal que tiene capacidad de decidir la consecución, mantenimiento o modificación del estado de cosas (cf. Dik, 1989: 96).
} 
prodicado disponga prototípicamente del rasgo semántico [+animado], que actúa como restricción de selección. El output resultante nos ofrece un predicado que, conscrvando las características originarias, se ve ahora incrementado por el afijo aplicativo -i- y complementado por un término beneficiario.

Adcmás de los argumentos gramaticales que he esgrimido en estas páginas, creo que mi hipótesis se ve avalada también por otros datos de naturaleza lexicológica. En suahclí, algunas de las formas derivadas llegan a adquirir normativamente un signilicado propio no deducible a partir de la regla de formación. Un caso de este lipo es el de la raíz AMK ('despertar'). De ella deriva AMKl, que significa literalmente 'despertar [para alguien]', pero cuya traducción más apropiada es 'saludar' (por la mañana), 'dar los buenos días'. Otros ejemplos similares serían los siguientes:

(18)a) SHIRIK ('agruparse', 'asociarse'): SHIRIKI ('participar', 'compartir').

b) HAM ('cmigrar'): HAMI ('mudarse [a algún sitio]').

c) PAK ('untar'): PAKI ('extender', 'pintar').

d) TUM ('enviar'): TUMI ('usar').

Todos los ejemplos mencionados se ajustan plenamente a la regla (17), por lo que se refiere a su vertiente estrictamente gramatical. Eventualmente, tal regla deberá completarse con ciertas estrategias semántico-pragmáticas —en la línea, por cjemplo, de lo señalado por Dik (1978: 68-71) — que expliquen el proceso que ha dado lugar al significado traslaticio de la unidad derivada ${ }^{29}$.

Otro detalle importante es que este proceso no se aplica solamente a raíces de naturaleza verbal. Ashton (1944: 217) señala la posibilidad de derivar verbos de este tipo a partir de ciertos nombres de origen árabe. Los arabismos léxicos son, como muy bien se sabe, abundantísimos en suahelí, por lo que la formación de verbos aplicativos de base nominal no debe resultar nada infrecuente. Ahora bien, a tenor de lo que puede observarse en los próximos ejemplos, tengo la impresión de que, al menos ocasionalmente, tal procedimiento se extiende también a raíces nominales no arábigas (19b y c), o incluso a otras clases de palabras (19d):

(19)a) huruma ('compasión'): hurumi ('apiadarse [de alguien]', lit.: 'tener compasión [para alguien]').

b) СНUмв^ ('habitación"): СНUмвı ('prometerse en matrimonio [con alguien]', lit.: 'tener (dispuesta) una habitación [para alguien]').

c) CHUKI ('malhumor, cólera'): CHUKIA ('odiar, aborrecer [a alguien/algo]').

29 Estas estrategias habrán de atender, entre otras cuestiones, el hecho de que el predicado AMK ('despertar'), que en condiciones normales define un estado de cosas carente de control, pase a ser reinterpretado como un estado de cosas controlado y, con ello, responda a las condiciones de aplicación de la regla (17). 
d) KARIBU (NA/YA) ("cerca (de), junto a, jadelante!'): KARIBIA ('acercarse [a alguien]').

Para los casos recogidos en este último bloque la regla (17) resulta inadecuada. Su comportamiento ha de explicarse, consecuentemente, por medio de otra regla (derivada del anterior) en la que el input y las condiciones de aplicación resulten acordes con la aparición de raíces léxicas no verbales. En cualquier caso, tanto en la regla originaria (17) como en la derivada el output ha de responder a una misma caracterización estructural: un verbo incrementado por el afijo -i-, que describe un estado de cosas controlado y que está complementado por un constituyente que ha recibido la función semántica beneficiario. Ahora bien, mientras que la regla (17) es aplicable en sincronía a un conjunto de unidades potencialmente abierto (todos los predicados verbales que definan estados de cosas controlados) la regla derivada sólo es aplicable a un conjunto cerrado de raíces no verbales que, en virtud de la evolución de la norma idiomática del suahelí, han sido seleccionadas como base de la formación de nuevos verbos incrementados con el mencionado afijo.

\section{Conclusiones}

En el presente artículo he procedido a revisar, a grandes rasgos, las claves teóricas que subyacían a la doctrina tradicional de las funciones gramaticales, y las causas que han dado lugar a su cuestionamiento y revisión por parte de la lingüística moderna. Asimismo, he prestado particular atención al papel que Simon C. Dik asigna a las funciones sintácticas en el marco teórico de la GF. Este último, sin renunciar en modo alguno a una concepción gramatical acorde con el paradigma funcionalista, introduce novedades de muy hondo calado, por las cuales las funciones sintácticas dejan de ser entendidas como universales. Así, la GF contempla exclusivamente dos funciones sintácticas (sujeto y objeto), cuya presencia en las lenguas particulares está vinculada, con las restricciones impuestas por una jerarquía de funciones semánticas (JFS), a sendos procesos de alternancia de diátesis ( $o$, en términos de Dik, 'cambio de perspectiva'): la pasividad y la ascensión de dativo. Dado que este último proceso diatético no está documentado en español, habrá que concluir, entre otras cosas, que nuestra lengua carece de lo que la GF llama función objeto.

Por lo que se refiere al caso concreto de las lenguas bantúes, he puesto de manifiesto cómo, en líneas generales, ofrecen un comportamiento bastante complejo en lo relativo a la asignación de la función sintáctica objeto. El modelo dikeano ha interpretado estos hechos sobre la base de un proceso diacrónico de cambio de marca. Esto permitiría hablar de la existencia en estas lenguas de una ergatividad de objeto, en la medida en que en ellas se verifica, respecto a dicha 
lunción sintáctica, un proceso análogo al que manifiestan las lenguas ergativas respecto de la función sujeto. Ahora bien, cabe señalar que dentro de las lenguas bantúcs se pueden distinguir dos grupos: el primero de ellos (representado, entre otras lenguas, por $\mathrm{el} \mathrm{chona} \mathrm{y} \mathrm{el} \mathrm{chimuini)} \mathrm{sí} \mathrm{se} \mathrm{ajusta} \mathrm{plenamente} \mathrm{a} \mathrm{las} \mathrm{previsiones}$ derivadas de la teoría del cambio de marca; en cambio, el segundo grupo (en el que se encuentran el quiñaruanda y el suahelí) presenta ciertas características que exigen un análisis específico. Así, en suahelí la mayor dificultad estriba en el valor que debe asignarse al afijo aplicativo $-\mathrm{i}-$, presente en todas las predicaciones en las que se documenta un constituyente con función semántica beneficiario. Dik interpreta dicho morfema como una marca de asignación de objeto a tal constituyente, a pesar de que ello comporta cierto grado de artificiosidad en el mancjo de los propios postulados de la GF. Por mi parte, considero que dicha postura es difícilmente sostenible. Por un lado, conduce a una interpretación a todas luces contraintuitiva del funcionamiento de la voz pasiva en suahelí; por otro, las muestras de lengua que he consignado en este artículo ponen de relieve que las condiciones teóricas exigidas para conceder validez en este punto a la hipótesis dikeana -que los afijos pronominales actúen como marcas de asignación de objeto y que en suahelí la función semántica receptor sea en la práctica totalmente irrelcvante- no se verifican realmente. Por este motivo, mi propuesta se encamina a considerar cl afijo - $\mathrm{i}$ - como un procedimiento de formación de predicados derivados. Procedimiento que habría de actuar en el componente de base de la gramática y que vendría condicionado por la presencia de un término beneficiario en la predicación. Esta hipótesis vendría apoyada, además, por el hecho de que algunos verbos incrementados con el afijo aplicativo ofrecen un significado traslaticio respecto del verbo de origen, y por la constatación de que ciertas raíces léxicas no verbales pueden dar lugar, mediante la aplicación del mismo afijo, a verbos derivados análogos. Todos estos datos parecen confirmar que nos cncontramos más ante un mecanismo de lexicogénesis, productivo sincrónicamentc, que ante un proceso sintáctico, en sentido estricto, para la asignación de la lunción objeto.

\section{Referencias bibliográficas:}

Alarcos Llorach, Emilio (1968): «Verbo transitivo, verbo intransitivo y estructura del predicado», en Estudios de gramática funcional del español. Madrid: Gredos, $1987^{3}, 148-162$.

Ashton, E. O. (1944): Swahili Grammar. Londres: Longman, 1977.

Bresnan, Joan (ed.) (1982): The Mental Representation of Grammatical Relations. Cambridge (Mass.): The MIT Press. 
Chervel, André (1977): Histoire de la grammaire scolaire. París: Payot.

Chevalier, Jcan-Claude (1968): Histoire de la Syntaxe. Naissance de la notion de complément dans la grammaire française (1530-1750): París: Droz.

Chomsky, Noam (1965): Aspectos de la teoría de la sintaxis. Madrid: Aguilar, 1970.

Comrie, Bernard (1982): «Grammatical relations in Huichol», en Hopper, Paul J. y Sandra A. Thomson (eds.), Studies in transitivity (Syntax and Semantics, vol. 15): Nueva York: Academic Press, 95-115.

Dik, Simon C. (1968): Coordination. Its implications for the theory of General Linguistics. Amsterdam: North Holland, 1972.

Dik, Simon C. (1978): Gramática funcional. Madrid: SGEL, 1981.

Dik, Simon C. (1989): The Theory of Functional Grammar. Dordrecht: Foris.

Dik, Simon C. (1997): The Theory of Functional Grammar. 2 vols. Edición a cargo de Kees Hengeveld. Berlín: Mouton de Gruyter.

Ertel, Suitbert (1977): "Where do the subjects of sentences come from?», en Rosenberg, Sheldon (ed.), Sentence Production: Developments in Research and Theory. Hillsdale (N.J.): Lawrence Earlbaum.

Fillmore, Chatles F. (1968): «The case for case», en Bach, E., y Harms, R. T. (eds.), Universals in Linguistic Theory. Nueva York: Holt, Rinehart \& Winston, i-88.

Gary, Judith Olmsted y Edward L. Keenan (1977): «On collapsing grammatical relations in universal grammar», en Cole, Peter y Jerrold M. Sadock (eds.), Grammatical relations (Syntax and Semantics, vol. 8): Nueva York: Academic Press, 83-120.

Gruber, J. S. (1976): Lexical Structures in Syntax and Semantics. Amsterdam: North Holland [basado en la Tesis Doctoral titulada Studies in Lexical Relations, defendida en el MIT en 1965].

Gutiérrez Ordóñez, Salvador (1983): «La determinación inmanente de las funciones en sintaxis», en Principios de sintaxis funcional. Madrid: Arco Libros, 1997, 77-92.

Helbig, Gerdhard (1968): «Zum Funktionsbegriff in der modernen Linguistik», en Deutsch als Frendsprache, 5/6, 274-287.

Hengeveld, Kees (1992): Non-Verbal Predication. Berlín: Mouton de Gruyter. Hjelmslev, Louis (1928): Principios de gramática general. Madrid: Gredos, 1976. Hoekstra, Tcun (1984): Transitivity. Grammatical Relations in GovernmentBinding Theory. Dordrecht: Foris.

Kimenyi, Alexandre (1988): «Passiveness in kinyarwanda», en Shibatani, M. (ed.), Passives and voice. Amsterdam: John Benjamins, 364-374.

Kuno, Susumu (1987): Functional Syntax: Anaphora, Discourse, and Empathy.

Chicago: University of Chicago Press. 
Lenz, Rodolfo (1920): La oración y sus partes. Madrid: Centro de Estudios Históricos, $1935^{3}$.

Martinet, André (1960): Elementos de lingüística general. Madrid: Gredos, 1970.

Martínez Marín, Juan (1988): «Sintaxis y paradigmática (con especial referencia a la lengua española)», en $L E A, \mathrm{X}, 10-21$.

Morcno Cabrera, Juan Carlos (1990): Lenguas del mundo. Madrid: Visor.

Norman, William N. (1978): «Advancement rules and syntactic change in Mayan», en $B L S, 4,458-476$.

Olbertz, Hella, Kees Hengeveld y Jesús Sánchez García (eds.) (1998): The Structure of the Lexicon in Functional Granmar. Amsterdam: John Benjamins.

Postal, Paul y David M. Perlmutter (1974): Lectures on Relational Grammar. Summer Linguistic Institute of the Linguistic Society of America, Amherst (Mass.): University of Massachussets Press.

Real Academia Española (RAE) (1920): Gramática de la lengua castellana (31 ${ }^{\mathrm{a}}$ ed.): Madrid: Sucesores de Hernando.

Schuchardt, Hugo (1893): Baskische Studien I. Über die Entstehlung der Bezungsformen des Baskischen Zeitsworts, en Denkschr. der Wien. Ak. (Memorias de la Academia de Viena), 42.3, 1-82.

Schuchardt, Hugo (1895): «Über den passiven Charakter des Transitivs in den Kaukasischen Sprachen», en SB des Wien. Ak. (Actas de la Academia de Viena), 133.1, 1-91.

Siewierska, Anna (1991): Functional Grammar. Londres: Routledge.

Tesnic̀re, Lucicn (1959): Éléments de Syntaxe Structurale. París: Klincksieck, 1988.

Van Pelt, Piet (1985): Gramática swahili. Madrid: Mundo Negro, 1992. 